\title{
CORRECTION
}

\section{The interwoven history of mercury poisoning in Ontario and Japan}

CMAJ would like to clarify aspects of the article "The interwoven history of mercury poisoning in Ontario and Japan," by Adam Mosa, published on Feb. 6, 2017. ${ }^{1}$ References 9 and 10 were listed in the incorrect order. In addition, the article should have included a 12th reference. Reference 12 ("Brusser D, Poisson J. Signs of mercury poisoning in Grassy Narrows youth, say Japanese experts. The Star [Toronto]; 2016
Sept. 20) supports the statement: "More recently, in 2014, the Japanese research team found high rates of Minamata disease symptoms attributable to mercury poisoning in young residents of Grassy Narrows." This has been corrected at cmaj.ca.

- Cite as: CMAJ 2017 March 27;189:E475. doi: $10.1503 / \mathrm{cmaj} .170204$

\section{Reference}

1. Mosa A. The interwoven history of mercury poisoning in Ontario and Japan. CMAJ 2017;189: E213-5. 